\title{
Pengaruh Kualitas Pelayanan, Lokasi dan Harga Terhadap Kepuasan Pelanggan Hotel 101 Suryakencana Bogor
}

\author{
Raynaldo Donovan S. dan Adil Fadillah \\ Program Studi Manajemen, Institut Bisnis dan Informatika Kesatuan \\ Bogor, Indonesia
}

E-Mail: raynaldoseumahu @gmail.com

Submitted: FEBRUARI 2020

\begin{abstract}
ABSTRAK
Untuk dapat meningkatkan kepuasaan Pelanggan,perusahaan dituntut untuk memiliki strategi yang tepat agar dapat membangun hubungan yang baik dengan pelanggan nya. Kualitas pelayanan,Strategi Lokasi,dan Harga dapat menjadi faktor bagi perusahaan untuk meningkatkan kepuasaan pelanggan. Tujuan dari penelitian ini adalah (1) untuk mengetahui pengaruh kualitas pelayanan terhadap kepuasaan pelanggan Pada Hotel 101 di Suryakencana kota bogor,(2) untuk mengetahui pengaruh Strategi Lokasi terhadap kepuasaan pelanggan Pada Hotel 101 di Suryakencana kota bogor,(3) untuk mengetahui pengaruh Harga terhadap kepuasaan pelanggan pada hotel 101 di Suryakencana kota bogor,dan (4) untuk mengetahui pengaruh kualitas pelayanan,Strategi Lokasi,dan Harga secara bersama-sama terhadap kepuasaan pelanggan Hotel 101 di Suryakencana kota bogor. Jumlah responden dalam penelitian ini berjumlah 100 responden yang diambil dari seluruh pengunjung di Hotel 101 Suryakencana kota Bogor.Data penelitian ini diolah menggunakan SPSS 2018. Hasil dari penelitian sebagai berikut : (1) Kualitas pelayanan mempunyai pengaruh yang positif dan signifikan terhadap kepuasaan pelanggan Hotel 101 di Suryakencana kota bogor dengan nilai signifikan $0,004,(2)$ Strategi Lokasi mempunyai pengaruh yang positif dan signifikan terhadap kepuasaan pelanggan Hotel 101 di Suryakencana kota bogor dengan nilai signifikan 0,003 ,(3) Harga mempunyai pengaruh yang positif dan signifikan terhadap kepuasaan pelanggan Hotel 101 di Suryakencana kota bogor dengan nilai signifikan 0,000,(4) Kualitas pelayanan,Strategi Lokasi dan Harga secara bersama-sama berpengaruh positif dan signifikan terhadap kepuasaan pelanggan dengan nilai signifikan 0,000.(5) persamaan Regresi $\mathrm{Y}=3,330+0,158 \mathrm{X} 1+0,147 \mathrm{X} 2+0,231 \mathrm{X} 3$
\end{abstract}

KataKunci:Kualitas pelayanan,StrategiLokasi,Harga,dan Kepuasaan Pelanggan

\section{PENDAHULUAN}

Pemasaran jasa merupakan kegiatan perusahaan yang diarahkan untuk memenuhi kebutuhan dan keinginan konsumen. Pemasaran jasa telah menjadi subjek yang sangat penting dalam kelansungan usaha perusahaan, sejalan dengan semakin berkembangnya perekonomian. Kita telah mengetahui pemasaran jasa mempunyai peran penting bagi suatu perusahan,baik perusahan pemerintah maupun swasta. Industri perhotelan adalah industri jasa yang memadukan antara

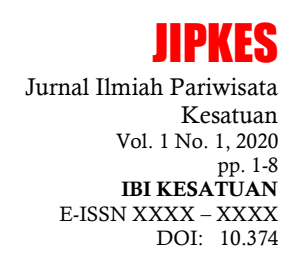

Accepted: APRIL 2020 
Hotel's

Customer

Satisfaction

2

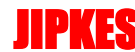

Jurnal Ilmiah Pariwisata Kesatuan

Vol. 1 No. 1, 2020

pp. 1-8

IBI KESATUAN

E-ISSN XXXX - XXXX

DOI: produk dan layanan desain (interior) dan (eksterior) kamar hotel.Fasilitas yang ada merupakan contoh produk yang dijual.sedangkan layanan yang dijual adalah keramah-tamahan dan keterampilan staff/karyawan hotel dalam melayani pelanggannya. seseorang yang muncul setelah membandingkan antara persepsi atau kesan terhadap kinerja atau hasil suatu produk dan harapanharapannya(kotler dan keller 2009) jadi kepuaasan merupakan fungsi dari persepsi atau kesan atas kinerja dan harapan.

Disamping itu kualitas pelayanan yang baik juga turut berperan dalam menjaring konsumen. Dengan adanya kualitas pelayanan yang baik di dalam suatu perusahaan, akan menciptakan kepuasan bagi para konsumennya. Setelah konsumen merasa puas dengan produk atau jasa yang diterimanya, konsumen akan membandingkan pelayanan yang diberikan. Apabila konsumen merasa benar-benar puas, mereka akan membeli ulang serta memberi rekomendasi kepada orang lain untuk membeli di tempat yang sama..Menurut Tjiptono(2014) persepsi yang diperoleh dari interaksi pelanggan dengan fasilitas berpengaruh terhadap kualitas jasa tersebut dimata pelanggan.

Dalam membangun sebuah usaha diperlukan sebuah tempat dimana sebuah perusahaan tersebut akan berlokasi.Mayoritas dari pengguna jasa hotel adalah mereka yang berasal dari luar daerah yang sedang memiliki urusan disekitar hotel itu berada baik untuk tujuan wisata,bisnis, ataupun hanya untuk tempat istirahat sementara.karena itu lokasi hotel yang strategis akan memudahkan konsumen untuk mendapatkan akses terhadap hotel tersebut.kedekatan hotel dengan tempattempat wisata akan menjadi nilai tinggi bagi perusahaan.

Kepuasan pelanggan atau pengunjung muncul setelah membandingkan antara kinerja atau hasil produk yang dipikirkan terhadap kinerja atau hasil yang diharapkan. Jika kinerja berada dibawah harapan, maka pengunjung merasa tidak puas. Sebaliknya, jika kinerja memenuhi harapan konsumen atau pengunjung akan merasa puas. Meningkatnya kepuasan konsumen, akan meningkatkan pula kecenderungan konsumen untuk kembali menggunakan produk atau jasa yang ditawarkan perusahaan. Pada gilirannya, kondisi seperti ini akan berdampak pada performa bisnis perusahaan. Peningkatan jumlah konsumen menjadi asset yang sangat berharga bagi perusahaan dalam meningkatkan profitabilitas. Hal tersebut menyebabkan tugas untuk memahami sifat konsumen dan mengamati perubahan selera dan perilaku mereka menjadi tantangan manejerial yang tidak ringan

Salah satu hotel yang sedang berkembang pesat di bogor adalah hotel 101 yang terletak di suryakencana Bogor.lokasi hotel yang strategis karena berada di jantung pusat wisata kuliner seperti lokal food,chinese food,jajanan pasar,dan juga café disekitar suryakencana.Hotel 101 juga menyediakan fasilitas yang tidak kalah dengan para pesaing nya seperti fasilitas Kolam renang,resto,parkiran,wifi. Tingkat persaingan yang tinggi di bidang jasa perhotelan menyebabkan konsumen memiliki banyak pilihan sehingga menuntut pihak hotel untuk mengidentifikasi faktor-faktor yang dapat mempengaruhi konsumen untuk menginap serta menerapkan strategi-strategi yang tepat untuk meningkatkan jumlah tamu yang menginap. pelayanan hotel 101 Bogor mendapatkan skor yang cukup tinggi yaitu 9.0 dari review para pelanggan hotel,begitu juga skor dari lokasi dan harga mendapatkan nilai yang cukup tinggi yaitu 8.4 untuk lokasi dan 8.0 Harga.

Dengan begitu adanya kemungkinan para pelanggan hotel 101 Bogor merasakan kepuasan pelanggan dari segi pelayanan,lokasi,dan harga. Lokasi dari hotel 101 Bogor berada ditempat yang strateigis karena dekat dengan tempat tempat wisata, sarana transportasi, dan pusat perbelanjaan. Dimana tempat - 
tempat disekitar hotel 101 Bogor banyaknya titik - titik kemacetan yang membuat para pelanggan merasa kurang nyaman yang ditakutkan mempengaruhi berkurangnya kepuasan pelanggan. Dari fenomena ini maka peneliti tertarik untuk meneliti dengan studi kasus hotel 101 Bogor. Terdapat keluhan-keluhan pelanggan terhadap hotel 101 baik dari kualitas pelayanan yang diberikan dan lokasi akses menuju hotel.Hotel 101 harus mampu menangapi keluhan pelanggan secara cepat agar tidak ada lagi keluhan yang terjadi dari pelanggan dan bisa membuat pelanggan merasa puas dengan apa yang diberikan Hotel 101 suryakencana Bogor.

Berdasarkan beberapa uraian diatas maka dilakukan penelitian untuk mengetahui faktor-faktor yang mempengaruhi seseorang menginap di hotel. Maka penulis tertarik melakukan penelitian dengan judu "PengaruhKualitas Pelayanan,Strategi Lokasi, dan Harga Terhadap Kepuasaan pelanggan. (studi kasus Hotel 101 Suryakencana Bogor). Tujuan dari pada penelitian ini adalah sebagai berikut:

1. Untuk mengetahui pengaruh kualitas pelayanan terhadap kepuasaan pelanggan.

2. Untuk mengetahui berapa besar pengaruh Strategi Lokasi terhadap Kepuasaan pelanggan

3. Untuk mengetahui berapa besar pengaruh Harga terhadap Kepuasaan pelanggan

4. Untuk mengetahui berapa besar pengaruh kualitas pelayanan,Strategi Lokasi,dan Harga secara bersama-sama terhadap kepuasaan pelanggan.

Menurut Kotler \& Keller (2009), "Kepuasaan pelanggan adalah tingkat perasaan seseorang setelah membandingkan kinerja (atau hasil) yang ia rasakan dibandingkan dengan harapannya" Sedangkan menurut Howard dan Sheth (1998) mengungkapkan bahwa "Kepuasaan pelanggan adalah situasi kognitif pembeli berkenaan dengan kesepadanan atau ketidaksepadanan antara hasil yang didapatkan dibandingkan dengan pengorbanan yang dilakukan".

Menurut Lewis dan Booms yang dikutip Tjiptono (2014) yaitu, "Kualitas jasa sebagai ukuran seberapa bagus tingkat layanan yang diberikan mampu sesuai dengan ekspetasi konsumen". Menurut Kotler (2009) Salah satu kunci menuju sukses adalah lokasi, lokasi dimulai dengan memilih komunitas. Keputusan ini sangat bergantung pada potensi pertumbuhan ekonomis dan stabilitas, persaingan, iklim politik, dan sebagainya. Menurut Kotler (2012) metode penentuan harga dapat didekati dengan menseleksi harga akhir dengan menambahkan faktor-faktor diantaraanya Psychological pricing di mana konsumen menggunakan harga sebaga indicator kualitas dan kebijaksanaan harga kepada tenaga penjualan untuk diberikan kepada konsumen dan untuk profitabilitas perusahaan.

\section{METODE PENELITIAN}

Penelitian ini menggunakan metode deskriptif dan metode kuantitatif. Sumber data yang digunakan dalam penelitian ini adalah data primer dan data sekunder. Data primer penelitian ini antara lain adalah data karakteristik responden dan data persepsi responden yang berminat maupun pelanggan Hotel 101 Suryakencana Bogor. Data sekunder dalam penelitian ini berupa studi kepustakaan, penelitian terdahulu dan literatur-literatur yang berkaitan dengan Kualitas Pelayanan, Strategi Lokasi dan Harga.

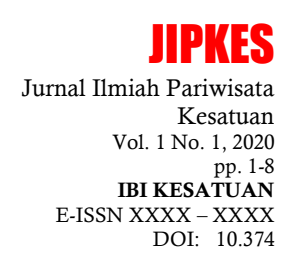


Hotel's

Customer

Satisfaction

$\underline{4}$

\section{JIPKES}

Jurnal Ilmiah Pariwisata Kesatuan

Vol. 1 No. 1,2020

pp. $1-8$

BI KESATUAN

E-ISSN XXXX - XXXX DOI:
Metode pengumpulan data yang dilakukan dalam penelitian ini adalah: (1) Observasi, (2) Wawancara, (3) Dokumentasi. Berkaitan dengan penelitian ini, penulis membuat metode penelitian dengan menggunakan analisis jalur (path analysis) yang merupakan suatu teknik analisis statistika yang dikembangkan dari analisis regresi berganda dengan menggunakan variabel endogen dan eksogen. Dalam pengelolaan data dan kuesioner digunakan alat analisis yaitu software SPSS Statistic 24 dalam mencari tanggapan responden mengenai Kualitas Pelayanan, Strategi Lokasi dan Harga

\section{HASIL DAN PEMBAHASAN Profil Responden}

Untuk menggambarkan responden yang mengisi kuisioner di bawah ini disajikan profil responden sebagai berikut: Responden pria sebanyak 46 responden(46\%), dan responden wanita sebanyak 54 responden (54\%). Responden yang berusia 17-20 tahun sebanyak 23 responden (23\%),responden yang berusia 21-30tahun sebanyak 23 responden (23\%),responden yang berusia 30-40tahun sebanyak 28 responden (28\%), dan responden yang berusia diatas 40 tahun sebanyak 26 responden (26\%). Responden dengan pendidikan terakhir <SMA sebanyak 27 responden (27\%),responden dengan pendidikan Diploma sebanyak 33 responden (33\%),responden dengan pendidikan sarjana sebanyak 36responden (36\%),responden dengan pendidikan magister sebanyak 4 responden (4\%).

Responden dengan profesi swasta sebanyak 16 responden(16\%),responden dengan profesi PNS sebanyak 44 responden (44\%),responden dengan profesi Mahasiswa sebanyak 22 responden (22\%), dan responden dengan profesi wirausaha sebanyak 17 responden (18\%). Responden dengan status belum menikah sebanyak 55 responden (55\%),dan yang sudah menikah sebanyak 45 responden (45\%). Responden yang memiliki pendapatan perbulan $<$ Rp 2.000 .000 sebanyak 20 responden (20\%),responden yang memiliki pendapatan Rp 2.000.000-Rp3.000.000 sebanyak 47 responden (47\%),responden yang memiliki pendapatan $\mathrm{Rp}$ 3.000.000-Rp 5.000.000 sebanyak 29 responden(29\%),dan responden yang memiliki pendapatan $\mathrm{R} p>5.000 .000$ sebanyak 4 responden (4\%).

\section{Koefisien Korelasi dan Koefisien Determinasi}

Analisa korelasi berfungsi untuk mengetahui bagaimana hubungan antara Kualitas Pelayanan (X1), Strategi Lokasi (X2), Harga (X3) terhadap Kepuasaan Pelanggan (Y).

Tabel 1 Tabel Koefisien Korelasi dan Koefisien Determinasi

\begin{tabular}{lcrrr}
\hline Model & R & R Square & Adjusted R Square & Std. Error of the Estimate \\
\hline 1 & $.863^{\mathrm{a}}$ & .744 & .736 & 2.267 \\
\hline
\end{tabular}

a. Predictors: (Constant), Kualitas Pelayanan, Strategi Lokasi, Harga

b. Dependent Variable: Kepuasaan Pelanggan

Sumber : Data Pridomer Diolah

Dapat dijelaskan bahwa hubungan atau korelasi berganda pada seluruh variabel (Kualitas pelayanan, Strategi Lokasi, Harga dan Kepuasaan pelanggan), memiliki kekuatan hubungan yang sangat kuat. Hal ini dilihat berdasarkan nilai koefisien korelasi berganda sebesar 0,863. Perolehan nilai r-square sebesar 0,744 dapat dijelaskan bahwa variabel Kualitas pelayanan, Strategi Lokasi , Harga dan Kepuasaan pelanggan mampu mempengaruhi atau menjelaskan keragaman (variabilitas) nilai dari Kualitas pelayanan sebesar 0,736 atau 73,6\% sedangkan sisanya sebesar $26,4 \%$ dipengaruhi atau dijelaskan oleh variabel lain yang tidak diteliti. 


\begin{tabular}{|c|c|c|c|c|c|c|}
\hline \multicolumn{7}{|c|}{ ANOVA $^{\mathrm{a}}$} \\
\hline \multicolumn{2}{|c|}{ Model } & $\begin{array}{l}\text { Sum of } \\
\text { Squares }\end{array}$ & df & $\begin{array}{l}\text { Mean } \\
\text { Square }\end{array}$ & $\mathrm{F}$ & Sig. \\
\hline \multirow[t]{3}{*}{1} & Regression & 1434.856 & 3 & 478.285 & 93.087 & $.000^{\mathrm{b}}$ \\
\hline & Residual & 493.254 & 96 & 5.138 & & \\
\hline & Total & 1928.110 & 99 & & & \\
\hline
\end{tabular}

a. Dependent Variable: Kepuasaan pelanggan

b. Predictors: (Constant), Harga, Kualitas pelayanan, Strategi Lokasi

Berdasarkan tabel 2. hubungan antara Kualitas pelanggan, Strategi Lokasidan Harga dengan Kepuasaan pelanggan diperoleh f-hitung 93.087 dan lebih besar dari f-tabel $(\mathrm{df} 1=3, \mathrm{df} 2=97, \alpha=5 \%)=2,70$; dan didukung oleh nilai signifikansi sebesar 0,000 dan lebih kecil dari $(\alpha=5 \%)=0,05$ dengan demikian H0 ditolak dan H1 diterima. Dengan demikian Kualitas Pelayanan, Strategi Lokasidan Hargasecara bersama-sama mempunyai pengaruh terhadap Kepuasaan pelanggan maka hipotesis diterima.

Persamaan regresi berganda adalah hubungan secara linier antara dua atau lebih variabel independen (X1, X2, X3) dengan variabel dependen (Y). Analisis ini untuk mengetahui arah hubungan antara variabel independen apakah masingmasing variabel independen berhubungan positif atau negative untuk memprediksi nilai dari variabel dependen apakah nilai variabel independen mengalami kenaikan atau penurunan.

Tabel 3. Hasil Uji Regresi

\begin{tabular}{|c|c|c|c|c|c|c|}
\hline \multicolumn{7}{|c|}{ Coefficients $^{\mathrm{a}}$} \\
\hline \multirow{2}{*}{\multicolumn{2}{|c|}{ Model }} & \multicolumn{2}{|c|}{$\begin{array}{l}\text { Unstandardized } \\
\text { Coefficients }\end{array}$} & \multirow{2}{*}{$\begin{array}{c}\text { Standardized } \\
\text { Coefficients } \\
\text { Beta } \\
\end{array}$} & \multirow[b]{2}{*}{$\mathrm{t}$} & \multirow[b]{2}{*}{ Sig. } \\
\hline & & $\mathrm{B}$ & Std. Error & & & \\
\hline \multirow[t]{4}{*}{1} & (Constant) & 3.330 & 1.252 & & 2.659 & .009 \\
\hline & Kualitas pelayanan & .158 & .064 & .275 & 2.471 & .004 \\
\hline & Strategi Lokasi & .147 & .072 & .249 & 2.039 & .003 \\
\hline & Harga & .231 & .058 & .390 & 4.010 & .000 \\
\hline
\end{tabular}

a. Dependent Variable: Kepuasaan pelanggan

Berdasarkan Tabel 3 dapat ditentukan persamaan regresi berganda untuk penelitian ini sebagai berikut :

$\mathrm{Y}=3,330+0,158(\mathrm{X} 1)+0,147(\mathrm{X} 2)+0,231(\mathrm{X} 3)$

Model tersebut menunjukkan arti bahwa:

Konstanta $=3,330$

Nilai konstanta sebesar 3,330 menunjukkan bahwa tanpa melibatkan variabel Kualitas pelayanan,Strategi Lokasi dan Harga,atau dengan kata lain jika skor kualitas pelayanan,Strategi Lokasi dan Harga adalah nol,maka kepuasaan pelanggan nilainya positif yaitu 3,330.

Koefisien Kualitas pelayanan $X_{1}$

Nilai koefisien variabel kualitas pelayanan sebesar 0,158 menyatakan bahwa setiap peningkatan kualitas pelayanan sebesar satu dengan asumsi nilai variabel Strategi Lokasi dan Harga Tetap,maka kepuasaan pelanggan akan meningkat sebesar 0,158

Koefisien Strategi Lokasi $X_{2}$

Nilai koefisien variabel Strategi Lokasi sebesar 0,147 menyatakan bahwa setiap peningkatan Strategi Lokasi sebesar satuan dengan asumsi nilai variabel kualitas

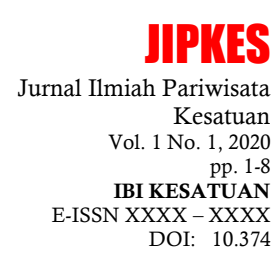


Hotel's

Customer

Satisfaction

$\underline{6}$

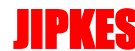

Jurnal Ilmiah Pariwisata Kesatuan

Vol. 1 No. 1,2020

pp. $1-8$

IBI KESATUAN

E-ISSN XXXX - XXXX

DOI: pelayanan dan Harga tetap,maka kepuasaan pelanggan akan meningkat sebesar 0,147

Koefisien Harga $X_{3}$

Nilai koefisien variabel Harga sebesar 0,231 menyatakan bahwa setiap peningkatan Harga sebesar satuan dengan asumsi nilai kualitas pelayanan dan Strategi Lokasi tetap,maka kepuasaan pelanggan akan meningkat sebesar 0,231.

Analisis Asosiasi Antar Variabel

Pengaruh antara Kualitas Pelayanan (X1) terhadap Kepuasaan pelanggan(Y) Hipotesis Penelitian 1 Kualitas Pelayanan berpengaruh positif dan signifikan terhadap Kepuasaan Pelanggan

\begin{tabular}{ll}
\hline H0 $: b 1=0$ & $\begin{array}{l}\text { Kualitas Pelayanan tidak mempunyai } \\
\text { pengaruh dengan Kepuasaan Pelanggan }\end{array}$ \\
\hline H1 $: b 1 \neq 0$ & $\begin{array}{l}\text { Kualitas Pelayanan mempunyai pengaruh } \\
\text { dengan Kepuasaan Pelanggan }\end{array}$ \\
\hline
\end{tabular}

Berdasarkan hasil analisis hubungan antara Kualitas Pelayanan (X1) dengan Kepuasaan pelanggan( $(\mathrm{Y})$ diperoleh $\mathrm{t}$ hitung sebesar 2.471 dan lebih besar t-tabel $(\mathrm{df}=\mathrm{n}-\mathrm{k}-1$ atau $\mathrm{df}=100-3-1=96 ; \alpha=5 \%)=1,96$ atau 2.471> 1,96; H0 ditolak dan H1 diterima. Kesimpulan hipotesis penelitian pertama diterima, berarti ada pengaruh yang positif dan signifikan antara Kualitas Pelayanan (X1) dengan Kepuasaan pelanggan (Y). Penelitian ini berdasarkan hasil uji statistik diatas hipotesis pertama yang berbunyi Kualitas Pelayanan berpengaruh positif dan signifikan terhadap Kepuasan Pelanggan. Hal ini ditunjukkan dengan nilai thitung sebesar 2.471 yang dimana lebih besar dibandingkan t-tabel 1.96 dan didukung oleh nilai signifikansi 0.04 lebih kecil dibandingkan 0.05 yang dimana variabel tersebut berpengaruh positif dan signifikan terhadap Kepuasaan Pelanggan maka hipotesis pertama diterima.

Pengaruh antara Strategi Lokasi (X2) terhadap Kepuasaan Pelanggan(Y)

Hipotesis Penelitian 2 Strategi Lokasi berpengaruh positif dan signifikan terhadap Kepuasaan pelanggan

\begin{tabular}{ll}
\hline H0 $: \mathrm{b} 2=0$ & $\begin{array}{l}\text { Strategi Lokasi tidak mempunyai pengaruh } \\
\text { dengan Kepuasaan pelanggan }\end{array}$ \\
\hline H1 $: \mathrm{b} 2 \neq 0$ & $\begin{array}{l}\text { Strategi Lokasi mempunyai pengaruh dengan } \\
\text { Kepuasaan pelanggan }\end{array}$ \\
\hline
\end{tabular}

Berdasarkan hasil analisis Pengaruh antara Strategi Lokasi (X2) dengan Kepuasaan pelanggan(Y) diperoleh thitung sebesar 2.039 dan lebih besar t-tabel $(\mathrm{df}=\mathrm{n}-\mathrm{k}-1$ atau $\mathrm{df}=100-3-1=96 ; \alpha=5 \%)=1,96$ atau 2.039>1,96; H0 ditolak dan $\mathrm{H} 2$ diterima. Kesimpulan hipotesis penelitian kedua diterima, berarti ada pengaruh yang positif dan signifikan antara Strategi Lokasi (X2) dengan Kepuasaan Pelanggan. Penelitian ini berdasarkan hasil uji statistik diatas hipotesis pertama yang berbunyi Strategi Lokasi berpengaruh positif dan signifikan terhadap Kepuasan Pelanggan. Hal ini ditunjukkan dengan nilai t-hitung sebesar 2.039 yang dimana lebih besar dibandingkan t-tabel 1.96 dan didukung oleh nilai signifikansi 0.003 lebih kecil dibandingkan 0.05 yang dimana variabel tersebut berpengaruh positif dan signifikan terhadap Kepuasaan pelanggan maka hipotesis kedua diterima.

Pengaruh antara Harga (X3) terhadap Kepuasaan Pelanggan(Y)

\begin{tabular}{ll}
\hline Hipotesis Penelitian 3 & $\begin{array}{l}\text { Harga berpengaruh positif dan signifikan } \\
\text { terhadap Kepuasaan Pelanggan }\end{array}$ \\
\hline H0 $: \mathrm{b} 3=0$ & $\begin{array}{l}\text { Harga tidak mempunyai pengaruh dengan } \\
\text { Kepuasaan Pelanggan }\end{array}$ \\
\hline
\end{tabular}




\begin{tabular}{lll}
\hline $\mathrm{H} 1$ & $: \mathrm{b} 3 \neq 0$ & $\begin{array}{l}\text { Harga mempunyai pengaruh dengan } \\
\text { Kepuasaan pelanggan }\end{array}$
\end{tabular}

Berdasarkan hasil analisis Pengaruh antara Harga (X3) dengan Kepuasaan Pelanggan(Y) diperoleh $\mathrm{t}$ hitung sebesar 4.010 dan lebih besar t-tabel (df=n-k-1 atau $\mathrm{df}=100-3-1=96 ; \alpha=5 \%)=1,96$ atau 4.010> 1,96; H0 ditolak dan H3 diterima. Kesimpulan hipotesis penelitian ketiga diterima, Penelitian ini berdasarkan hasil uji statistik diatas hipotesis pertama yang berbunyi Harga berpengaruh positif dan signifikan terhadap Kepuasan PelangganHal ini ditunjukkan dengan nilai t-hitung sebesar 4.010 yang dimana lebih kecil dibandingkan t-tabel 1.96 dan didukung oleh nilai signifikansi 0.000 lebih kecil dibandingkan 0.05 yang dimana variabel tersebut berpengaruh positif dan signifikan terhadap Kepuasaan pelanggan maka hipotesis ketiga diterima

Pengaruh antara Kualitas Pelayanan (X1), Strategi Lokasi (X2) dan Harga (X3) secra simultan terhadap Kepuasaan Pelanggan (Y)

\begin{tabular}{ll}
\hline Hipotesis Penelitian 4 & $\begin{array}{l}\text { Kualitas Pelayanan, Strategi Lokasi dan } \\
\text { Harga berpengaruh positif dan signifikan } \\
\text { terhadap Kepuasaan pelanggan }\end{array}$ \\
\hline H0 :b4 $=0$ & $\begin{array}{l}\text { Kualitas Pelayanan, Strategi Lokasi dan } \\
\text { Harga tidak mempunyai pengaruh dengan } \\
\text { Kepuasaan pelanggan }\end{array}$ \\
\hline H1 :b4 $\neq 0$ & $\begin{array}{l}\text { Kualitas pelayanan, Strategi Lokasi dan Harga } \\
\text { mempunyai pengaruh dengan Kepuasaan } \\
\text { pelanggan }\end{array}$ \\
\hline
\end{tabular}

Berdasarkan hasil analisis pengaruh Kualitas Pelayanan, Strategi Lokasi dan Harga dengan Kepuasaan pelanggan diperoleh nilai F-hitung 93.087 dan lebih besar dari $\mathrm{F}$ tabel $(\mathrm{df} 1=3, \mathrm{df} 2=96, \alpha=5 \%)=2,70$; dan didukung oleh nilai signifikansi sebesar 0,000 dan lebih kecil dari $(\alpha=5 \%)=0,05$ dengan demikian H0 ditolak dan H4 diterima. Dengan demikian Kualitas Pelayanan, Strategi Lokasidan Harga secara bersama-sama mempunyai pengaruh terhadap Kepuasaan pelanggan maka hipotesis diterima.

\section{PENUTUP}

Penelitian ini menguji pengaruh Kualitas Pelayanan, Strategi Lokasi,Dan Harga terhadap Kepuasan Pelanggan simpulan dari hasil penelitian ini adalah sebagai berikut:

1. Kualitas pelayanan berpengaruh positif dan signifikan terhadap kepuasaan pelanggan dengan nilai dengan nilai t hitung 2,471>t tabel 1,96 Hotel $101 \mathrm{di}$ kota Bogor

2. Strategi Lokasi berpengaruh Positif dan signifikan terhadap kepuasaan pelanggan dengan nilai t hitung 2,039>t tabel 1,96 Hotel 101 di kota bogor.

3. Harga berpengaruh positif dan signifikan terhadap kepuasaan pelanggan dengan nilai t hitung 4,010>t tabel 1,96 Hotel 101 dikota bogor

4. Kualitas pelayanan,Strategi Lokasi dan Harga secara bersama-sama berpengaruh positif dan signifikan terhadap kepuasaan pelanggan dengan nilai F hitung sebesar 93,087 dan dengan tingkat signifikansi 0,000.

\section{DAFTAR PUSTAKA}

Ali, H. (2013). Marketing dan kasus-kasus pilihan. Yogyakarta. CAPS (Center For Academic Publishing Service).
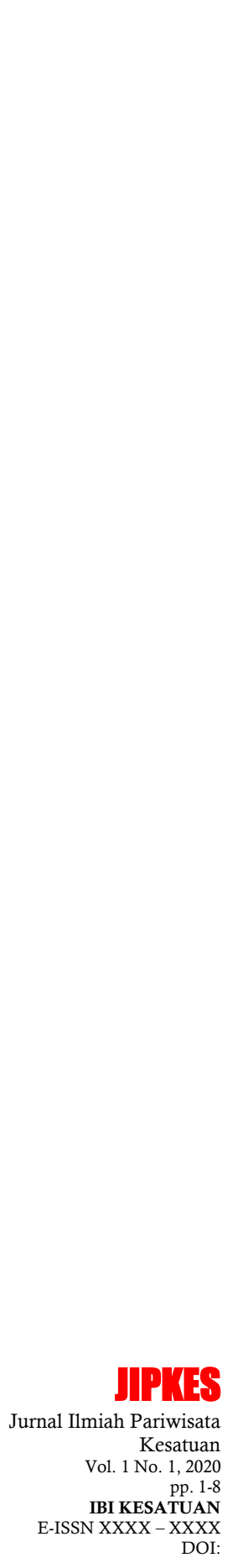
Hotel's

Customer

Satisfaction

$\underline{8}$

\section{JIPKES}

Jurnal Ilmiah Pariwisata

Kesatuan

Vol. 1 No. 1,2020

pp. 1-8

IBI KESATUAN

E-ISSN XXXX - XXXX

DOI:
}

Barata, Atep Adya. 2004. Dasar - Dasar Pelayanan Prima. Jakarta : PT Elex Media Komputindo.

Goetsch \& Davis 2013 Quality management,Fourth edition.cram101 Incoporated

Gronroos, Christian.2010.service management and marketing:Customer Management in service. Third edition,john Wiley \& Sons.

Ghozali,Imam.2009.Aplikasi Analisis Multivariate dengan program IBM SPSS. Badan penerbit Universitas Diponegoro,Semarang.

Hermawan,Asep dan Husna Leila Yusran.2017.penelitian bisnis pendekatan kuantitatif.kencana,Depok.

Hermawan, Kertajaya. "Marketing Plus 2000." Siasat Memenangkan Persaingan Global (2002).

Irawan, Handi, 2009, Sepuluh Prinsip Kepuasan Pelanggan, Penerbit Elex Media Komputindo Kelompok Gramedia Jakarta

Kotler, P. (2012). Kotler on marketing. Simon and Schuster.

Kotler,Philip dan keller,kevin Lane.2009.Manajemen pemasaran.edisi ketiga belas jilid 1. Penerjemah: Bob Sabran,MM.Erlangga,Jakarta.

Kotler , Philip; and Amstrong Garry.2012,prinsip-prinsip pemasaran.Edisi 13.Jilid 1.jakarta:Erlangga

Lovelock, C., dan Gummesson. (2011). Pemasaran Jasa (Seventh ed.). Erlangga

Lovelock, C., (2011). Pemasaran Jasa 2 (Seventh ed.). Erlangga

Lupiyoadi,Rambat,(2013):Manajemen pemasaran jasa.jakarta:Salemba Empat.

Lupiyoadi, C., \& Hamdani, A. (2008). Marketing Management Services.

Levy,weitz,2007, Retailing management, New York,McGraw-Hill

Solomon, Michael R. (2011). Consumer Behavior : Buying, Having and Being, 9th ed, New Jersey: Pearson Addison Wesley.

Sugiyono. 2014. Metode Penelitian Kuantitatif, Kualitatif, dan R\&D. Bandung: Penerbit Alfabeta.

Tjiptono,Fandy 2014. Pemasaran jasa-prinsip, penerapan, dan penelitian ANDI, Yogyakarta

Markadikawanti,woro,dan Farida Nailil.2013.pengaruh Nilai pelanggan dan kualitas layanan terhadap loyalitas pelanggan,melalui kepuasaan pelanggan pada pelanggan Bus Efisiensi (Studi PO efieisiensi Jurusab Yogyakartacilacap).Jurnal Administrasi BIsnis.Vol 2(1):64-75

Hardiyanti, Ratih. (2010). Analisis Pengaruh Kualitas Pelayanan Terhadap Kepuasan Konsumen Menggunakan Jasa Penginapan (Villa) Agrowisata Kebun Teh Pagilaran. Universitas Diponegoro.

Rayi Endah. 2008. Pengaruh kualitas layanan, kualitas produk, dan harga terhadap kepuasan pelanggan restoran warung Taman Singosari Semarang. Universitas Dipenegoro Semarang.jurnal stratification vol 1(1)

Swastika (2005). Pengaruh Pelayanan Prima (Service Exellent) Terhadap Kepuasan Pelanggan. Jurnal Skripsi Ekonomi.

Adi, S., Martani, D., Pamungkas, B. and Simanjuntak, R.A., 2016. Analysis of the quality of performance report of the local government on websites: Indonesian case. Cogent Business \& Management, 3(1), p.1229393.

Iriyadi, I., 2019. Prevention of Earnings Management through Audit Committee and Audit Quality in the Award-Winning and Non-Winning Companies. Journal of Accounting Research, Organization and Economics, 2(2), pp.155-169. 